\title{
Electroreduction of lead(II) ions on lead electrode in the presence of surfactants and different electrolytes
}

\author{
Aizhan Mamyrbekova ${ }^{a}$, Makhabat Kassymova ${ }^{\mathrm{b}}$, Aigul Mamyrbekova $^{\mathrm{a}, *}$, Aigul Mamitova $^{\mathrm{c}}$, \\ Rabiga Pralieva $^{\mathrm{d}}$, Gauhar Mutasheva ${ }^{\mathrm{e}}$ \\ a Department of Laboratory Disciplines, Faculty of Dentistry, Khoja Akhmet Yassawi International \\ Kazakh-Turkish University, Turkestan 161200 Kazakhstan \\ b Department of Chemistry, Higher School of Natural Science and Pedagogy, Auezov South-Kazakhstan \\ State University, Shymkent 160012 Kazakhstan \\ c Department of Life Safety and Environmental Protection, Faculty of Construction and Transport, Auezov \\ South-Kazakhstan State University, Shymkent 160012 Kazakhstan \\ d Department of General Disciplines, Prefaculty, Khoja Akhmet Yassawi International Kazakh-Turkish \\ University, Turkestan 161200 Kazakhstan \\ e Department of Ecology and Life Safety, Faculty of Transport Engineering and Construction, Kazakh \\ Transport and Communications Academy, Almaty 050000 Kazakhstan
}

*Corresponding author, e-mail: aigul.mamyrbekova@ayu.edu.kz

Received 16 Jan 2020

Accepted 3 Nov 2020

\begin{abstract}
The influence of high molecular weight water-soluble surfactants with different functional groups on the electroreduction of lead(II) ions on a lead electrode in various electrolytes was studied. A copolymer of methacryloylaminophenol with acrylic acid, a leather waste hydrolyzate, and a copolymer of monoethanolamine with vinyl ether acetate were used as surfactants. The electrolytes used were $1 \mathrm{M} \mathrm{KCl}, \mathrm{KBr}, \mathrm{KNO}_{3}, \mathrm{HCOONa} \mathrm{NH}_{2} \mathrm{SO}_{3} \mathrm{H}$, $0.5 \mathrm{M} \mathrm{Na}_{2} \mathrm{SO}_{4}$, and $0.35 \mathrm{M} \mathrm{Na}_{3} \mathrm{C}_{6} \mathrm{H}_{5} \mathrm{O}_{7} \cdot 2 \mathrm{H}_{2} \mathrm{O}$. It was demonstrated that in $1.0 \mathrm{M} \mathrm{KCl}$ or $\mathrm{KBr}$ solutions, there was no inhibition of the electroreduction of lead(II) ions by the adsorption layers of surfactants. It was found that the inhibitory effect of polymers on the electroreduction of lead(II) ions in different background electrolytes increases in the order $\mathrm{KCl}<\mathrm{KBr}<\mathrm{Na}_{3} \mathrm{C}_{6} \mathrm{H}_{5} \mathrm{O}_{7} \cdot 2 \mathrm{H}_{2} \mathrm{O}<\mathrm{Na}_{2} \mathrm{SO}_{4}<\mathrm{KNO}_{3}<\mathrm{HCOONa}<\mathrm{NH}_{2} \mathrm{SO}_{3} \mathrm{H}$.
\end{abstract}

KEYWORDS: lead ions, electroreduction, surfactants, electrolyte, lead electrode

\section{INTRODUCTION}

Surfactants are widely utilized to enhance the cathodic deposits of metals and alloys in order to obtain coatings with desired physicochemical properties, and as additives to electrolytes, they are employed for metal refining and as corrosion inhibitors $[1,2]$. A great number of studies have recently been devoted to the influence of surfactants on electrode processes [3,4]. Most of them reflect the influence of surfactants on electrode processes of low-molecular compounds, and only a few discuss the influence of surfactants on electrode processes of high-molecular compounds [5, 6].

In recent years, there has been increased interest in studies on additions of water-soluble polymers with several functional groups having different properties, which provide high adsorption capacity on electrodes and have an appreciable effect on the electrode reactions $[7,8]$. It has been observed that the presence of surfactants makes it difficult for electrode processes to progress, as it produces an inhibitory effect explained by the blocking of the electrode's surface $[9,10]$. The inhibitory effect of organic additives also depends on a number of other factors, such as composition of the electrolyte [11, 12]. The inhibitory effect of the additive depends on the nature of the anions of the electrolyte, so it is impossible to predict continuation of the effect of inhibition in different electrolytes $[13,14]$. If we know the general patterns of the organic substances' influence on the anions of a background electrolyte and their interaction with them, we can interpret the mechanism of electrode processes and, in some cases, adjust the rate of electrochemical reactions [15-17].

Therefore, study of the electroreduction of metal ions on electrodes in the presence of polymer additives with several functional groups that 
provides the necessary physical and chemical properties of the electrolyte (scattering power, viscosity, electric conductivity) is very important from both theoretical and practical perspectives. The aim of this work is to study the influence of a number of surfactants on the rate of lead electroreduction on a lead electrode in electrolytes, in the presence of different anions of the background electrolyte.

\section{MATERIALS AND METHODS}

The effects of a number of surfactants were studied: a copolymer of ethacryloylaminophenol with acrylic acid (CMAAP-AA) $(\mathrm{Mr}=15000-20000)$, a hydrolyzate of leather industry waste (HLIW), and a monoethanolamine vinyl ether acetate copolymer (VEMEA) ( $\mathrm{Mr}=50000-100000)$. The choice of polymer water-soluble surfactants (CMAAP-AA, HLIW, VEMEA) is due to the fact that they can create adsorption layers at the phase interface, characterized by a high concentration of functional groups, which results in their high adsorption and inhibitory properties.

Electrolytes of the following composition were studied: $1 \mathrm{M} \mathrm{KCl}, \mathrm{KBr}, \mathrm{KNO}_{3}, \mathrm{HCOONa}, \mathrm{NH}_{2} \mathrm{SO}_{3} \mathrm{H}$, $0.5 \mathrm{M} \mathrm{Na}_{2} \mathrm{SO}_{4}$, and $0.35 \mathrm{M} \mathrm{Na}_{3} \mathrm{C}_{6} \mathrm{H}_{5} \mathrm{O}_{7} \cdot 2 \mathrm{H}_{2} \mathrm{O}$. KCl and $\mathrm{KBr}$ were chosen as the background electrolytes, as a result of their strong adsorption activity. The accelerating effect of halogen ions on electrode processes is well known. $\mathrm{Na}_{3} \mathrm{C}_{6} \mathrm{H}_{5} \mathrm{O}_{7} \cdot 2 \mathrm{H}_{2} \mathrm{O}$ and HCOONa were chosen from among the organic acids, since they are inert; the $\mathrm{NO}_{3}^{-}$ion is a weakly adsorbable anion [18]. It was of interest to use $1.0 \mathrm{M} \mathrm{NH}_{2} \mathrm{SO}_{3} \mathrm{H}$ as the background electrolyte for comparison with other electrolytes, given that the inhibitory effect of the $\mathrm{SO}_{3} \mathrm{H}^{-}$ion in the presence of surfactants is strong. Furthermore, $\mathrm{Na}_{2} \mathrm{SO}_{4}$ as the background electrolyte was studied, since the $\mathrm{SO}_{4}^{2-}$ anion does not participate in adsorption [19].

The electrochemical behavior of lead(II) ions in the $0.067 \times 10^{-2}$ to $1.33 \times 10^{-2} \mathrm{wt} \%$ range of surfactant concentrations at $298-328 \mathrm{~K}$ was studied. The kinetics of the discharge of lead(II) ions on a polycrystalline lead electrode was investigated by measuring the polarization curves with a P-5827M potentiostat $[20,21]$.

\section{RESULTS AND DISCUSSION}

We studied the electrochemical behavior of lead(II) ions on lead electrode in the presence of selected surfactants in the field of concentration $6.7 \times 10^{-4}$ $1.33 \times 10^{-2} \mathrm{wt} \%$ at the temperature range, $T=298$ $328 \mathrm{~K}$. The surfactants are adsorbed on lead electrode and the area of maximum adsorption is in the range from -0.4 to $-1.0 \mathrm{~V}$. The potential of the zero charge of lead is $E_{\mathrm{q}=0}=-0.56 \mathrm{~V}$, and the equilibrium potential is $E_{\mathrm{p}}=-0.126 \mathrm{~V}$. Therefore, the discharge of lead(II) ions without surfactants occurs on the positively charged surface of the electrode.

The research of the electroreduction of lead(II) ions carried out on lead electrode in the $1.0 \mathrm{M} \mathrm{KCl}$, $1.0 \mathrm{KBr}, 0.35 \mathrm{M} \mathrm{Na}_{3} \mathrm{C}_{6} \mathrm{H}_{5} \mathrm{O}_{7} \cdot 2 \mathrm{H}_{2} \mathrm{O}$ demonstrated the absence of surfactant's influence on the discharge of lead(II) ions. This can be attributed to the high specific adsorption of halogenide ions on the surface of a lead electrode, which can compete with the adsorption of adsorbate molecules. The result is that no inhibition is observed. The depolarizing effect of halogenide ions on inhibition could be due to two phenomena. The first is the altered structure of the adsorption layer, caused by the adsorption of both halogenide ions and surfactant molecules. The second is associated with the catalytic action of halogen ions; their low content in solution accelerates the electrode process.

The polarization curves of the discharge of lead(II) ions in a solution of $0.5 \mathrm{M} \mathrm{Na}_{2} \mathrm{SO}_{4}$ in the presence of HLIW and without it on the lead electrode at $T=298 \mathrm{~K}$ indicate that the addition of HLIW into the solution inhibits the electrode process. Addition of a surfactant HLIW to the solution greatly inhibits the discharge of lead(II) ions, which is apparent from the falling reduction current and a substantial increase in polarization [22]. When the content of HLIW in the solution is increased, the degree of inhibition grows and the drop in the limiting current becomes greater in the region of negative potentials. The polarization curves of the electroreduction of lead(II) ions in the presence of HLIW are N-shaped, which is a characteristic of the discharge of lead(II) ions in the presence of nitrogen-containing surfactants. This confirms the assumption that the inhibition of the process is mainly due to nitrogen-containing functional groups in the structure of HLIW. This also manifests itself in a decrease in the diffusion current and voltage, which is stronger for HLIW than for CMAAP-AA and VEMEA.

A similar study was carried out in the presence of CMAAP-AA and VEMEA. The addition of polymer surfactants to the solution of electrolytes and increasing their concentrations lead to accelerated electrical recovery of lead(II) ions on the lead electrode. This is demonstrated by the rise in the recovery currents and decrease in polarization. The polarization curves of the discharge of lead(II) ions in HCOONa solution in the presence 

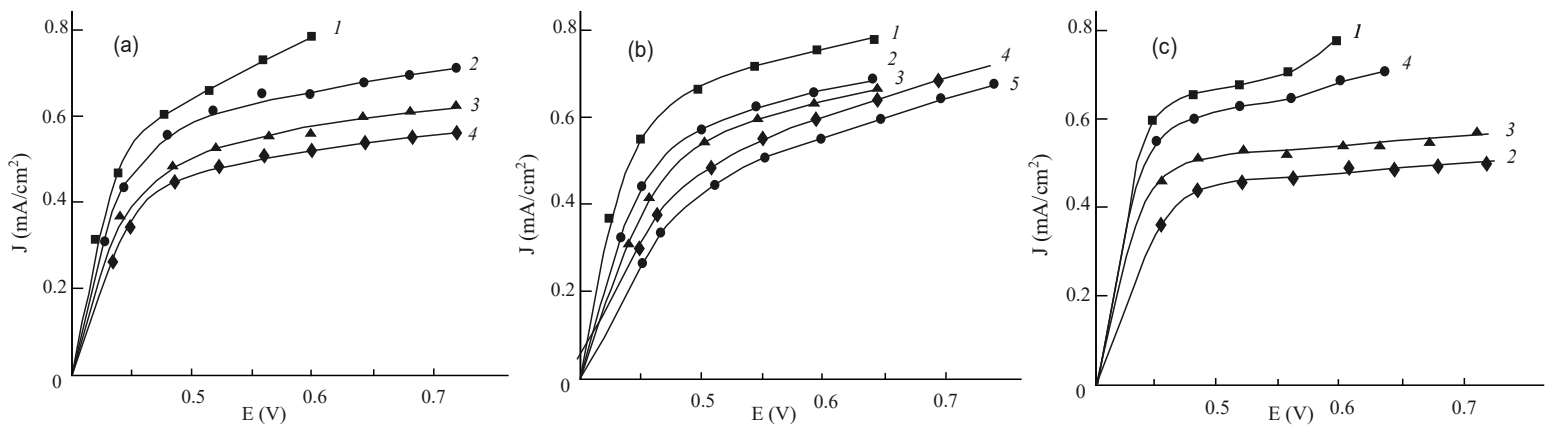

Fig. 1 Polarization curves for the electroreduction of lead(II) ions on a lead electrode obtained at $T=298 \mathrm{~K}$ on the background of $1.0 \mathrm{M}$ HCOONa in the presence or absence of surfactants: (a) CMAAP-AA, $C_{\text {surf }} \times 10^{3}$, wt $\%$ : (1) 0.00 , (2) 2.00, (3) 5.30, (4) 13.30; (b) HLIW, $C_{\text {surf }} \times 10^{3}$, wt\%: (1) 0.00, (2) 2.00, (3) 5.30, (4) 6.70, (5) 13.30; (c) VEMEA, $C_{\text {surf }} \times 10^{3}, \mathrm{wt} \%$ : (1) 0.00 , (2) 2.00 , (3) 5.30 , (4) 13.30 .

of polymeric surfactants and without them at $T=$ $298 \mathrm{~K}$ testify to the fact that the introduction of CMAAP-AA and VEMEA into the solution leads to inhibition of the discharge process of lead(II) ions. With an increase in the concentration of CMAAP-AA and VEMEA additives in the solution, the decrease in the limiting current increases and the polarization increases. With an increase in the content of these surfactants in the solution, the inhibitory effect of CMAAP-AA and VEMEA weakens. In the case of HLIW, the introduction of surfactants into the solution inhibits the process of lead(II) ions, accompanied by a decrease in recovery currents and an increase in polarization. With an increase in the concentration of the HLIW additive in solution, the degree of inhibition increases, and the decrease in the limiting current increases (Fig. 1).

In the presence of HLIW, a similar pattern is observed in solutions of $1.0 \mathrm{M} \mathrm{NH}_{2} \mathrm{SO}_{3} \mathrm{H}$ and $1.0 \mathrm{M}$ $\mathrm{KNO}_{3}$. It should be noted that in the presence of CMAAA-AA and VEMEA in a solution of $1.0 \mathrm{M}$ $\mathrm{NH}_{2} \mathrm{SO}_{3} \mathrm{H}$, the introduction of the copolymers additive leads to inhibition of the process, revealed by a decrease in the limiting recovery current. In this case, a slight increase in polarization is observed. With the increase in concentration of surfactant additives in solution, the degree of inhibition increases. However, with a surfactant concentration above $1.33 \times 10^{-2} \mathrm{wt} \%$, there is some weakening of the inhibitory effect of surfactants.

The constancy of $\alpha$ is an indirect evidence of the invariability of the lead(II) ions discharge mechanism in the presence of surfactants. Inhibition is carried out at the stage of penetration of the ions of the depolarizer into the surface layer [23]. The currents of exchange $j_{0}$ calculated under these conditions are
Table 1 The currents of exchange $\left(j_{0} \times 10^{3} \mathrm{~A} / \mathrm{cm}^{2}\right)$ for the electroreduction of lead(II) ions in various electrolytes in the presence or absence of CMAAP-AA at $T=298-328 \mathrm{~K}$.

\begin{tabular}{lccccccc}
\hline Electrolyte & $T(\mathrm{~K})$ & \multicolumn{6}{c}{$C_{\text {surf }} \times 10^{3}$, wt\% } \\
\cline { 3 - 8 } & & 0 & 2.0 & 4.0 & 5.3 & 7.0 & 13.3 \\
\hline $1.0 \mathrm{M} \mathrm{NH}_{2} \mathrm{SO}_{3} \mathrm{H}$ & 298 & 5.0 & 4.6 & 3.7 & 3.3 & 3.2 & 3.7 \\
& 308 & 5.1 & 5.4 & 5.3 & 4.4 & 3.9 & 3.8 \\
& 318 & 6.8 & 5.3 & 4.6 & 3.8 & 4.1 & 3.9 \\
& 328 & 6.3 & 6.3 & 4.2 & 4.7 & 4.7 & 4.7 \\
\hline $1.0 \mathrm{M} \mathrm{HCOONa}$ & 298 & 5.9 & 5.3 & 4.9 & 4.3 & 4.1 & 3.9 \\
& 308 & 6.4 & 5.9 & 5.7 & 5.6 & 5.8 & 5.7 \\
& 318 & 6.3 & - & - & - & - & - \\
& 328 & 6.7 & - & - & - & - & - \\
\hline
\end{tabular}

shown in Tables 1-3. An analysis of the data in Tables 1-3 shows that the rate of electroreduction of lead(II) ions, depending on the anion of the background without surfactant, decreases in a row (at all temperatures studied): $\mathrm{HCOONa}>\mathrm{KNO}_{3}>$ $\mathrm{NH}_{2} \mathrm{SO}_{3} \mathrm{H}>\mathrm{Na}_{3} \mathrm{C}_{6} \mathrm{H}_{5} \mathrm{O}_{7}>\mathrm{Na}_{2} \mathrm{SO}_{4}$.

Addition of a surfactant lowers the currents of exchange, indicating that this process is slowed. This is because an adsorption surfactant film is formed on the electrode's surface. The inhibitory effect of the surfactant additive depends on the nature of the electrolyte anions and on the nature of surfactants, containing various functional groups. In the presence of CMAAP-AA, its inhibitory effect in the researched electrolytes is enhanced in the following series:

$$
\mathrm{KNO}_{3}>\mathrm{HCOONa}>\mathrm{NH}_{2} \mathrm{SO}_{3} \mathrm{H}>\mathrm{Na}_{2} \mathrm{SO}_{4} .
$$
And in the case of the HLIW, it looks like:

$$
\mathrm{Na}_{2} \mathrm{SO}_{4}>\mathrm{KNO}_{3}>\mathrm{HCOONa}>\mathrm{NH}_{2} \mathrm{SO}_{3} \mathrm{H} \text {. }
$$

In the presence of a surfactant, the currents of exchange $j_{0}$ decrease. This indicates inhibition of 
Table 2 The currents of exchange $\left(j_{0} \times 10^{3} \mathrm{~A} / \mathrm{cm}^{2}\right)$ for the electroreduction of lead(II) ions in various electrolytes in the presence or absence of HLIW at $T=298-328 \mathrm{~K}$.

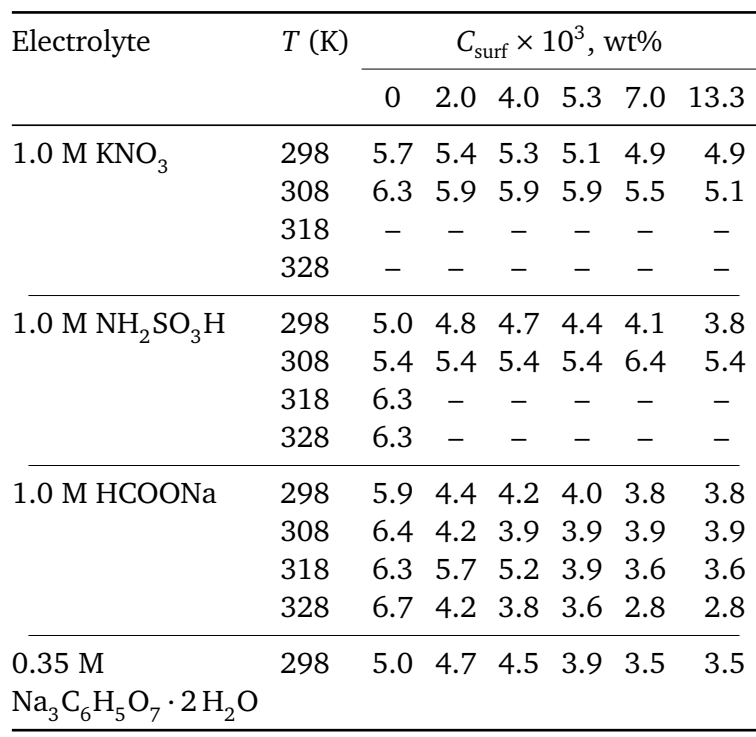

the electrode process.

To demonstrate the effect of temperature on the inhibitory properties of the considered surfactants, research of the discharge of lead(II) ions on a lead electrode at $T=308-328 \mathrm{~K}$ was carried out. The inhibitory effect in sulfanilic sour electrolyte is higher for the discharge of lead(II) ions than for cadmium(II), because sulfanilic acid forms more stable complexes with lead(II) ions than with cadmium(II) ions $[24,25]$.

The polarization curves of the electroreduction of lead(II) ions in the presence of HLIW and without it in the $1.0 \mathrm{M}$ HCOONa indicate that the inhibitory effect of the surfactant persists at $T=328 \mathrm{~K}$, i.e.
Table 3 The currents of exchange $\left(j_{0} \times 10^{3} \mathrm{~A} / \mathrm{cm}^{2}\right)$ for the electroreduction of lead(II) ions in various electrolytes in the presence or absence of VEMEA at $T=298-328 \mathrm{~K}$.

\begin{tabular}{lccccccc}
\hline Electrolyte & $T(\mathrm{~K})$ & \multicolumn{6}{c}{$C_{\text {surf }} \times 10^{3}, \mathrm{wt} \%$} \\
\cline { 3 - 7 } & & 0 & 2.0 & 4.0 & 5.3 & 7.0 & 13.3 \\
\hline $1.0 \mathrm{M} \mathrm{NH}_{2} \mathrm{SO}_{3} \mathrm{H}$ & 298 & 5.0 & 4.8 & 4.7 & 4.6 & 3.4 & 4.1 \\
& 308 & 5.4 & 4.9 & 4.8 & 4.7 & 4.5 & 4.5 \\
& 318 & 6.3 & 6.3 & 6.2 & 5.4 & 4.5 & 4.7 \\
& 328 & 6.3 & 6.4 & 5.9 & 5.8 & 4.8 & 4.8 \\
\hline $1.0 \mathrm{M} \mathrm{HCOONa}$ & 298 & 5.9 & 4.6 & 4.2 & 3.9 & 5.4 & 5.4 \\
& 308 & 6.4 & 5.4 & 5.4 & 5.2 & 5.1 & 7.0 \\
& 318 & 6.3 & 5.9 & 5.7 & 5.5 & 5.4 & 7.1 \\
& 328 & 6.7 & 6.9 & 6.2 & 5.9 & 5.5 & 7.4 \\
\hline
\end{tabular}

the temperature stability of the inhibitory effect of HLIW is evident. The inhibition is accompanied by an increase in polarization and a decrease in recovery currents. A similar picture was observed in the presence of VEMEA (Fig. 2). It should be noted that in the presence of CMAAP-AA, the degree of inhibition decreases with increase in temperature. Acceleration of the electrode process is observed. At low concentrations, CMAAP-AA (which has a carboxyl group) probably accelerates the process when adsorbed on an electrode with a positive carbon end and an oxygen end extending into the solution, due to the tightening effect negative particles having on lead(II) ions with the formation of intermediate complexes.

A similar study was carried out in solutions of $1.0 \mathrm{M} \mathrm{NH}_{2} \mathrm{SO}_{3} \mathrm{H}, 1.0 \mathrm{M} \mathrm{KNO}_{3}$, and $0.5 \mathrm{M} \mathrm{Na}_{2} \mathrm{SO}_{4}$. In the background of $1.0 \mathrm{M} \mathrm{NH}_{2} \mathrm{SO}_{3} \mathrm{H}$ at high concentrations of surfactants, a slight weakening of the inhibitory effect of surfactants was observed. However, the inhibition is quite pronounced. Moreover,
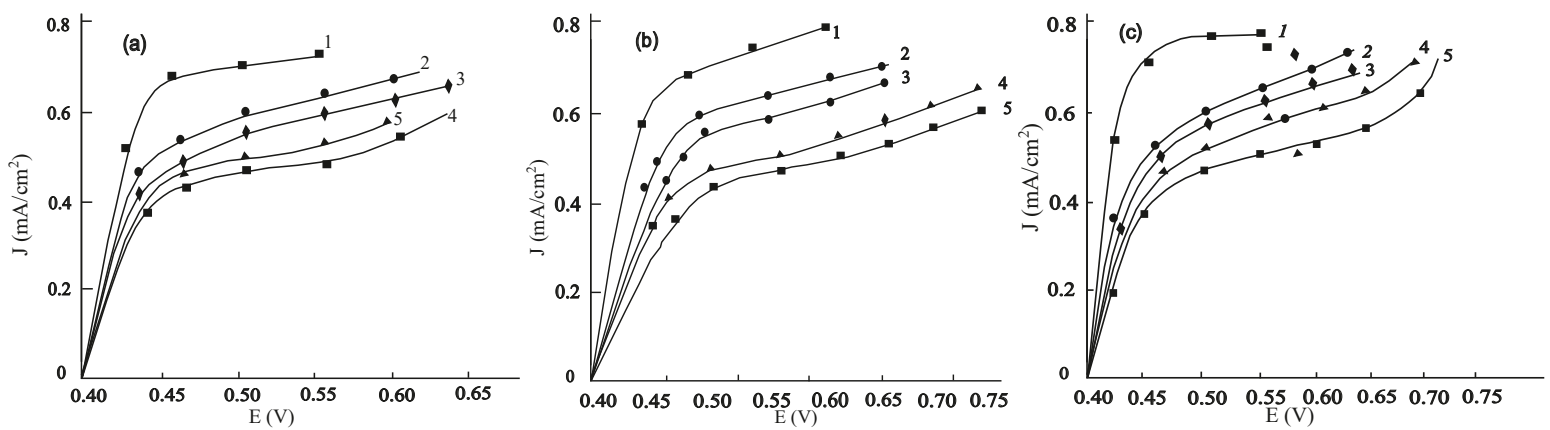

Fig. 2 Polarization curves for the electroreduction of lead(II) ions on a lead electrode obtained at $T=308-328 \mathrm{~K}$ on the background of $1.0 \mathrm{M}$ in the presence or absence of HLIW. (a) $T=308 \mathrm{~K}, C_{\text {surf }} \times 10^{3}$, wt\%: (1) 0.00 , (2) 2.00, (3) 5.30, (4) 6.70, (5) 13.30; (b) $T=318 \mathrm{~K}, C_{\text {surf }} \times 10^{3}$, wt\%: (1) 0.00, (2) 2.00, (3) 5.30, (4) 6.70, (5) 13.30; (c) $T=328 \mathrm{~K}$, $C_{\text {surf }} \times 10^{3}, \mathrm{wt} \%:$ (1) 0.00 , (2) 2.00 , (3) 5.30, (4) 6.70, (5) 13.30 . 


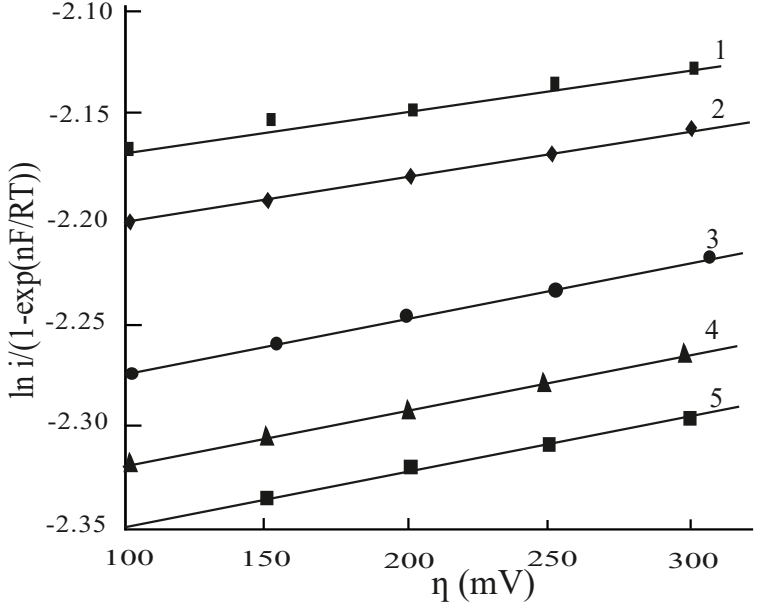

Fig. 3 Semilogarithmic dependences of the electroreduction of lead(II) ions at $T=298 \mathrm{~K}$ in the presence or absence of HLIW, $C_{\text {surf }} \times 10^{3}$, wt $\%$ : (1) 0.00 ; (2) 2.00 ; (3) 5.30 ; (4) 6.70 ; (5) 13.30 .

Table 4 The transfer coefficients $(\alpha)$ for the discharge process of lead(II) ions in various electrolytes at $T=298$ $328 \mathrm{~K}$ in the presence or absence of surfactants.

\begin{tabular}{lcccc}
\hline Surfactant & $T(\mathrm{~K})$ & $\mathrm{KNO}_{3}$ & $\mathrm{NH}_{2} \mathrm{SO}_{3} \mathrm{H}$ & $\mathrm{HCOONa}$ \\
\hline without & 308 & 0.66 & 0.40 & 0.50 \\
& 318 & 0.66 & 0.40 & 0.50 \\
& 328 & 0.66 & 0.47 & 0.55 \\
\hline CMAAP-AA & 308 & 0.66 & 0.40 & 0.50 \\
& 318 & 0.66 & 0.40 & 0.50 \\
& 328 & 0.66 & 0.41 & 0.55 \\
\hline HLIW & 308 & 0.66 & 0.40 & 0.50 \\
& 318 & 0.66 & 0.40 & 0.50 \\
& 328 & 0.66 & 0.40 & 0.55 \\
VEMEA & 308 & 0.66 & 0.40 & 0.50 \\
\hline & 318 & 0.66 & 0.40 & 0.50 \\
& 328 & 0.66 & 0.47 & 0.50 \\
\hline
\end{tabular}

the inhibition is accompanied by a decrease in the recovery current and an increase in polarization. In solutions of $0.5 \mathrm{M} \mathrm{Na}_{2} \mathrm{SO}_{4}$ and $1.0 \mathrm{M} \mathrm{KNO}_{3}$ in the presence of surfactants with an increase in temperature, the phenomenon of inhibition of electroreduction of lead(II) ions of the adsorption film is not observed. In solutions of $1.0 \mathrm{M} \mathrm{KCl}, \mathrm{KBr}$, no inhibition of the electroreduction of lead(II) ions of surfactant adsorption film was observed.

The semilogarithmic dependences $\ln i /(1-$ $\left.\mathrm{e}^{(n F \eta / R T)}\right)$ vs. $\eta$ for the discharge reaction of lead(II) ions with and without surfactants are linear and parallel to one another (Fig. 3); i.e., the mecha- nism behind the inhibition of the electroreduction of lead(II) ions in the presence of surfactants at high temperatures remains unchanged. The values of transfer coefficient, $\alpha$, for the discharge of lead(II) ions on a lead electrode remain constant. The constancy of $\alpha$ suggests that the mechanism of the discharge of lead(II) ions was not changed in the presence of surfactants. It is inhibited at the stage where depolarizer ions penetrate into the surface layer. The values of $\alpha$ calculated under these conditions are shown in Table 4.

The constancy of the values of $\alpha$ proves that the mechanism of the discharge process of lead(II) ions does not change. The change in the transfer coefficient testifies of the activation nature of polarization and on a more facilitated process at the stage of penetration of a depolarizer particle in a double electric layer (DEL) in the presence of a surfactant. The values of the currents of exchange $j_{0}$ calculated for these conditions are presented in Tables 2-4. An analysis of Tables 2-4 shows that in solutions of $1.0 \mathrm{M} \mathrm{NH}_{2} \mathrm{SO}_{3} \mathrm{H}$ and $1.0 \mathrm{M} \mathrm{HCOONa}$, the inhibitory effect of CMAAP-AA and VEMEA weakens with increase in temperature. The inhibitory effect of HLIW is also preserved at $T=328 \mathrm{~K}$. In solutions of $1.0 \mathrm{M} \mathrm{KNO}_{3}$ and $0.5 \mathrm{M} \mathrm{Na}_{2} \mathrm{SO}_{4}$, inhibition of the electroreduction of lead(II) ions by an adsorption surfactant film was not observed.

A temperature-kinetic analysis of the polarization curves was carried out for the temperature range $T=298-328 \mathrm{~K}$ (Fig. 4). Fig. 4 shows that the temperature-kinetic curves of the discharge of lead(II) ions in various electrolytes obtained at various overvoltages, in the absence of a surfactant, are straight linear and parallel to each other and independent of the overvoltage. The temperaturekinetic curves of the discharge of lead(II) ions in the presence of surfactants are straight linear. In the presence of surfactants, three main cases can be distinguished. The activation energy $\left(E_{\mathrm{a}}\right)$ is increased, which indicates the appearance of an additional potential barrier, i.e. an activation mechanism of inhibition occurs $[26,27]$. The activation energy decreases, i.e. the discharge of lead(II) ions is facilitated. The activation energy has a negative value; the temperature-kinetic curve has an inverse relationship. This is probably due to a decrease in the degree of filling of the electrode surface with surfactant molecules with the rise in temperature. The experimental data obtained allow us to conclude that the adsorption of the investigated surfactants leads to both the inhibition of the process of electroreduction of lead(II) ions on a lead electrode, 

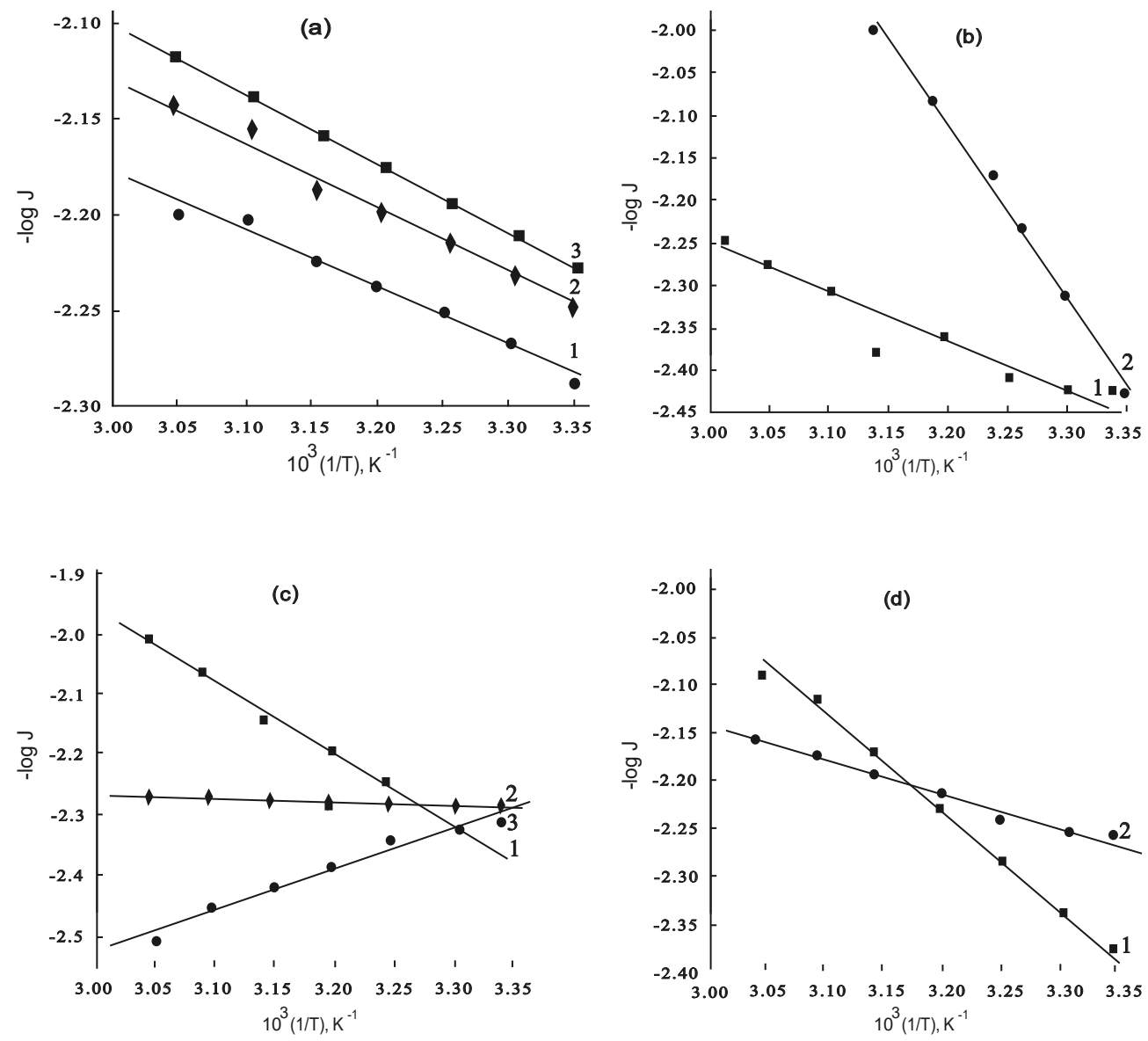

Fig. 4 Temperature-kinetic curves of electroreduction of lead(II) ions in various background electrolytes in the presence or absence of surfactants: (a) without surfactants; (b) CMAAP-AA; (c) HLIW; (d) VEMEA. 1, $1.0 \mathrm{M} \mathrm{NH}_{2} \mathrm{SO}_{3} \mathrm{H} ; 2,1.0 \mathrm{M}$ HCOONa; 3, $1.0 \mathrm{M} \mathrm{KNO}_{3}$.

and the acceleration of this process, depending on the nature of the additive and the conditions for electrolysis.

\section{CONCLUSION}

The features of influence of adsorption of watersoluble polymer surfactants: CMAAP-AA, HLIW and VEMEA on the electrode processes, particularly on the electroreduction of lead(II) ions show that the surface of the electrode is covered with adsorbed particles, the size of which significantly exceeds the size of the discharged ions. The density of the adsorption layers, characterized by the degree of filling of the electrode surface with surfactant molecules (ions), generally depends on the structure of the double electric layer, the volume concentration, as well as on the nature of the electrolyte and temperature conditions.

The obtained experimental data allow us to conclude that against the background of $1.0 \mathrm{M}$ $\mathrm{KCl}, 1.0 \mathrm{M} \mathrm{KBr}$, and $0.35 \mathrm{M} \mathrm{Na}_{3} \mathrm{C}_{6} \mathrm{H}_{5} \mathrm{O}_{7} \cdot 2 \mathrm{H}_{2} \mathrm{O}$, inhibition of the electroreduction of lead(II) ions by a surfactant adsorption film is not observed at the studied temperatures. In other cases, the rate of electroreduction of lead(II) ions, depending on the surfactant, decreases in the series: HLIW > CMAAPAA > VEMEA.

Temperature studies show that the discharge of lead(II) ions in the presence of surfactants obtained is also inhibited at $T=328 \mathrm{~K}$. It was established that the inhibitory effect of polymers on the electroreduction of lead II) ions in electrolytes increases in the following sequence: $\mathrm{KCl}<\mathrm{KBr}<$ $\mathrm{Na}_{3} \mathrm{C}_{6} \mathrm{H}_{5} \mathrm{O}_{7} \cdot 2 \mathrm{H}_{2} \mathrm{O}<\mathrm{Na}_{2} \mathrm{SO}_{4}<\mathrm{KNO}_{3}<\mathrm{HCOONa}$ $<\mathrm{NH}_{2} \mathrm{SO}_{3} \mathrm{H}$.

Acknowledgements: This research is funded by the Science Committee of the Ministry of Education and Science of the Republic of Kazakhstan (Grant No. AP08956404). 


\section{REFERENCES}

1. Frumkin AN, Damaskin BB (2003) Adsorption and Electric Double Layer in Electrochemistry, 2nd edn, Nauka, Moscow.

2. Wang J, Deo R, Thongngamdee S, Ogorevc B (2001) Effect of surface-active compounds on the stripping voltammetric response of bismuth film electrodes. Electroanalysis 13, 1153-1156.

3. Nieszporek J (2014) The inhibiting or accelerating effect of different surfactants on electroreduction of $\mathrm{Zn}^{2+}$. S Afr J Chem 67, 1-5.

4. Guideiii R, Foresti ML (1987) The inhibitrory effect of neutral organic surfactants upon simple electrode reactions. J Electroanal Chem 77, 73-96.

5. Sathyarayana S (1965) The retardation of electrochemical reactions by adsorbed organic molecules; a quantitative treatment involving the theory of irreversible polarographic. $J$ Electroanal Chem 10, 119-139.

6. Demeev BB, Dauletbay A, Nauryzbayev MK (2016) The effect of organic surface-active additives upon the kinetics of electrodeposition of ultrafine copper powder. Chem Eng Trans 47, 211-216.

7. Bojdi M, Mashhadizadeh M, Behbahani M, Farahani A, Davarani S, Bagheri A (2014) Synthesis, characterization and application of novel lead imprinted polymer nanoparticles as a high selective electrochemical sensor for ultra-trace determination of lead ions in complex matrixes. Electrochim Acta 136, 59-65.

8. Zirlianngura, Tiwari D, Ha J, Lee S (2017) Efficient use of porous hybrid materials in a selective detection of lead(II) from aqueous solutions: An electrochemical study. Metals 7, 4-7.

9. Drweesh MA (2004) Effect of surfactants on the removal of copper from waste water by cementation. Alex Eng $J$ 43, 917-925.

10. Lallemand F, Ricq L, Wery M, Berçot P (2015) The influence of organic additives on the electrodeposition of iron-group metals and binary alloy from sulfate electrolyte. Appl Surf Sci 228, 326-333.

11. Ivonina TA (2010) Investigation of the effect of a high-frequency electromagnetic field on the electrochemical behavior of heavy metal ions in the presence of surfactants. Russ J Electrochem 310, 318-328.

12. Guidelli R, Foresti M, Moncelli M (1980) On the inhibitory effect of neutral organic surfactants upon simple electrode reactions at high surface coverages. J Electroanal Chem 113, 171-191.

13. Dalbanbay A, Nefedov A, Nurmanova R, Nauryzbayev M (2017) Study of the influence of surfaceactive substances on the initial stage of copper electrodeposition. Chem Bull Kaz Nat Univ 4, 12-19.

14. Gyenge E, Oloman C (2001) Influence of surfactants on the electroreduction of oxygen to hydrogen peroxide in acid and alkaline electrolytes. $J$ Appl
Electrochem 31, 233-243.

15. Nagles E, Arancibia V, Ríos R, Rojas C (2012) Simultaneous determination of lead and cadmium in the presence of morin by adsorptive stripping voltammetry with a Nafion-ionic liquid-coated mercury film electrode. Int J Electrochem Sci 7, 5521-5533.

16. Gouveia-Caridade C, Brett CM (2006) The influence of Triton-X-100 surfactant on the electroanalysis of lead and cadmium at carbon film electrodes - An electrochemical impedance study. $J$ Electroanal Chem 592, 113-120.

17. Mamyrbekova A, Kassymova MK, Mamyrbekova A (2019) Effect of pH on the electroreduction of cadmium(II) and lead(II) ions on electrodes in the presence of surfactants. Russ $J$ Phys Chem 93, 442-446.

18. Kassymova MK, Nauryzbaev MK, Mamyrbekova A, Zhylysbayeva GN, Mamyrbekova A (2019) Effect of surfactants on the reduction of cadmium(II) ions on cadmium electrode. Russ $J$ Phys Chem 93, 980-985.

19. Zuman P (1995) Effects of solvents and surfactants on current-voltage curves obtained with DC and differential pulse polarography. Electroanalysis 7, 132-137.

20. Ziyatdinova G, Khuzina A, Budnikov H (2012) Determination of sterically hindered phenols and $\alpha$ tocopherol by cyclic voltammetry. Anal Lett 45, 1670-1685.

21. Seema-Mohammadi H, Apoorva MA, Ravishankar DR (2015) Effect of surfactants on the electrodeposited nickel composite coatings. Int J Tech Res Appl 3, 398-406.

22. Venkatesan KV, Damaskin BB, Nikolaeva Fedorovich MV (1990) Effect of adsorption of organic substances on the electroreduction of cations. J Electroanal Chem 25, 85-94.

23. Nikolic ND, Popov KI, Zivkovic PM, Brankovic G (2013) A new insight into the mechanism of lead electrodeposition: Ohmic-diffusion control of the electrodeposition process. J Electroanal Chem 691, 66-76.

24. Danilov FI, Vasil'eva EA, Butyrina TE, Protsenko VS (2010) Electrodeposition of lead-tin alloy from methanesulphonate bath containing organic surfactants. Prot Met Phys Chem Surf 46, 697-703.

25. Kozybaev AK, Tusupova BB, Abdikarimova AD (2014) Electrochemical reduction of cadmium ions(II) on cadmium electrode in the presence of polymeric surfactants at different temperatures. $A d v$ Environ Biol 8, 252-257.

26. Carlos IA, Siqueira JL, Finazzi GA, Almeida MR (2003) Voltammetric study of lead electrodeposition in the presence of sorbitol and morphological characterization. J Power Sources 117, 179-186.

27. Carlos IA, Malaquias MA, Oizumi MM, Matsuo TT (2001) Study of the influence of glycerol on the cathodic process of lead electrodeposition and on its morphology. J Power Sources 92, 56-64. 